\title{
Rapid rise and decay in petition signing
}

Taha Yasseri*, Scott A Hale and Helen Z Margetts

\author{
"Correspondence: \\ taha.yasseri@oii.ox.ac.uk \\ Oxford Internet Institute, University \\ of Oxford, 1 St Giles', Oxford, OX1 \\ 3JS, UK
}

\begin{abstract}
Contemporary collective action, much of which involves social media and other Internet-based platforms, leaves a digital imprint which may be harvested to better understand the dynamics of mobilization. Petition signing is an example of collective action which has gained in popularity with rising use of social media and provides such data for the whole population of petition signatories for a given platform. This paper tracks the growth curves of all 20,000 petitions to the UK government petitions website (http://epetitions.direct.gov.uk) and 1,800 petitions to the US White House site (https://petitions.whitehouse.gov), analyzing the rate of growth and outreach mechanism. Previous research has suggested the importance of the first day to the ultimate success of a petition, but has not examined early growth within that day, made possible here through hourly resolution in the data. The analysis shows that the vast majority of petitions do not achieve any measure of success; over 99 percent fail to get the 10,000 signatures required for an official response and only 0.1 percent attain the 100,000 required for a parliamentary debate (0.7 percent in the US). We analyze the data through a multiplicative process model framework to explain the heterogeneous growth of signatures at the population level. We define and measure an average outreach factor for petitions and show that it decays very fast (reducing to $0.1 \%$ after 10 hours in the UK and 30 hours in the US). After a day or two, a petition's fate is virtually set. The findings challenge conventional analyses of collective action from economics and political science, where the production function has been assumed to follow an S-shaped curve.
\end{abstract}

Keywords: petitions; collective action; e-democracy; big data; popularity dynamics; social contagion; multiplicative process

\section{Introduction}

Increasingly, collective action takes place in whole or at least in part online [1, 2], leaving transactional data that allow for new forms of analysis [3]. Studying the dynamics of protest recruitment through social media [4-6], modeling emergence and resolution of conflict in online mass collaboration projects [7, 8], characterizing online partisans [9], and quantifying 'collective emotions' [10] are some examples of the research based on these new type of data, which have been called 'big data' in the literature.

Petition-signing provides an example of a popular, low-cost act of political participation that is increasingly carried out digitally and shared via social media [11]. In this paper, we analyze growth patterns in petitions submitted to the UK Government on the central government portal (http://epetitions.direct.gov.uk) as well as the petitions submitted to the US White House site, We the People (https://petitions.whitehouse.gov). The UK

(c) The Author(s) 2017. This article is distributed under the terms of the Creative Commons Attribution 4.0 International License (http://creativecommons.org/licenses/by/4.0/), which permits unrestricted use, distribution, and reproduction in any medium, provided you give appropriate credit to the original author(s) and the source, provide a link to the Creative Commons license, and indicate if changes were made. 
electronic petition platform was developed by the UK Cabinet Office for the Coalition Government in 2010 and launched in August 2011. The petition platform replaced an earlier government platform on the No.10 Downing Street website, which was the first online petition platform operated by the UK government. The first platform ran from November 2006 until March 2011, during which time the site received more than 12 million signatures associated with over 5 million unique email addresses [12]. Both the No. 10 site and the Cabinet Office site have allowed anyone to view petitions and any user with a valid email address and UK postcode to create a new petition or to sign an existing petition. There are important differences between the sites, however. Whereas the first site showed the names of the 500 most recent signatories to a petition, the new site shows only the name of the petition creator (see Figure 1). The sites also have provided alternative measures for the 'success' of a petition. For the earlier, No. 10 site, the government guaranteed an official response to all petitions receiving at least 500 signatures, while for the new site the coalition government promised an official response at 10,000 signatures and that any petition attracting more than 100,000 signatures would qualify for a parliamentary debate on the issue raised.

\section{HMGovernment}

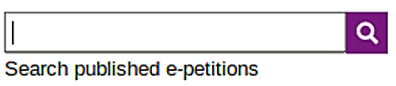

\section{e-petition}

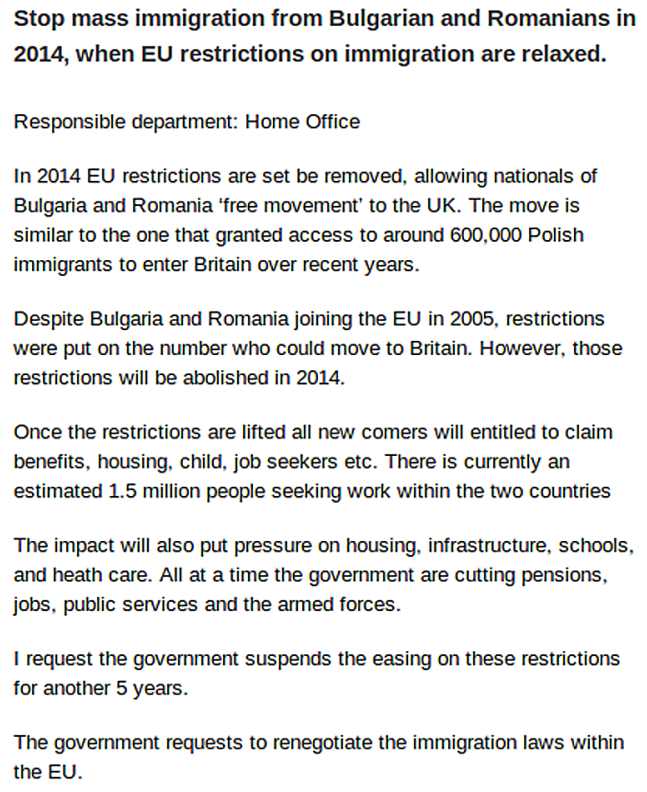

Number of signatures:

90,786

\section{Created by:}

Michael Fisher

Closing:

12/11/2013 12:04

Share:

\section{Sign this petition}

- Not received your confirmation email?

Figure 1 A snapshot of a petition on the http://epetitions.direct.gov.uk site. The platform was launched by the UK Cabinet Office for the Coalition Government in August 2011. 
The US petition platform We the People is hosted on the main White House website (whitehouse.gov) and allows any citizen to create or sign a petition to ask the administration to take action on a range of issues. The platform operates under a different arrangement, with higher bars to entry than in the United Kingdom and a shorter deadline for all petitions. The entry costs are higher, because petitioners must gain 100 signatures in order for their petition to be publicly searchable on the whitehouse.gov site. They are provided with an automatic email that they can forward to their immediate contacts to get started. After a petition is created, it has only thirty days to gain a hundred thousand signatures, the requirement for a White House response. In the first year since its launch on 22 September 2011, the platform generated 3.4 million signatures from 2.8 million users. The popularity of the facility was illustrated in its first week, when eight thousand petitions were created, racking up more than 600,000 signatures from 375,000 users. $^{a}$

In this paper we focus on the Cabinet Office UK petition website and the one in the US. In previous work [13] we analyzed data from the first UK website, finding that the number of signatures a petition received on its first day was pivotal to its ultimate success. The low threshold for success (500 signatures) and the coarse daily resolution of data on growth for the earlier site did not allow for an in-depth examination of the critical early moments of petitions. We note that the previous study of the No. 10 petition site found that the category of a petition or the day of week it was launched did not play a significant role in explaining the number of signatures a petition received [13]. In this paper, we undertake a new in-depth investigation of the early growth of petitions aided by the higher threshold for success on the new platform (100,000 vs 500 signatures) and a finer-grained capture of petition growth (hourly vs. daily resolution). Analysis of the second UK platform also allows us to compare its dynamics with those of the earlier platform, which we do throughout our analysis where possible, to find properties of petition growth that transcend any specific web platform.

\section{Background}

Signing petitions has long been among the more popular political activities, leading the field for participatory acts outside of voting [14]. In addition to the potential to bring about policy change, petition signing has had other social benefits ascribed to it such as reinforcing civic mindedness [15]. Online petitioning is one of a growing portfolio of Internetbased democratic innovations [16], and both governments and NGOs (e.g., Avaaz and 38 Degrees) have received accolades for their electronic petition platforms $[17,18]$.

The UK petition platforms have received little attention in recent political science research, with the exception of qualitative work by Wright [12, 19]. The German e-petition platforms have been analyzed more extensively [20, 21]. Jungherr and Jürgens [21] examined the distribution of signatures to the top petitions and found that while some successful petitions received most of their signatures shortly after launching, others received the bulk of their signatures later. Schmidt and Johnsen combined qualitative and quantitative methods to provide a typology for the petitions based on their dynamics [22].

Online petitions are examples of mobilizations with strong online imprints, which will include the entire transaction history for both successful and unsuccessful mobilizations. The data that can be harvested from the signing of electronic petitions represent a transactional audit trail of what people actually did (as opposed to what people think they did) and an entire population (without the need to take a representative sample). Data like this 
represents a shift for social science research into political behavior [23, 24], which has traditionally rested on survey data, or, for elections, voting data. These data make it possible to look at the different patterns of growth in more than 21,000 mobilization curves that we have and identify the distinctive characteristics of those mobilizations that succeed and those that fail with our digital hindsight. Such studies, using data that has rarely been available to political science researchers before the current decade, may tell us something about the nature of collective action itself in a digital world. Of the research noted above, Jungherr and Jürgens used a smaller dataset to illustrate the viability of a social data science (or computational social science) approach [21], but other studies used surveys [20] or more qualitative approaches [12].

\section{Data}

The UK Government's petition website was accessed hourly from 5 August 2011 to 22 February 2013 with an automated script. Every hour, the number of total signatures to date for each active petition was recorded. In addition, whenever a new petition appeared, the title of the petition, the name of the petitioner, the text of the petition, the launch date of the petition, and the government department at which the petition was directed were recorded. Overall, 19,789 unique petitions were tracked, representing all active petitions available publicly at any point during the study. The same procedure has been applied to the US petitions website leading to the collection of 1,811 petitions within the period of April 2013 to December 2014. All the data used in the paper are publicly available [25, 26].

\section{Results}

\subsection{Overall statistics}

A total of 7,303,019 signatures were collected for the 19,789 petitions in the UK and $12,974,475$ in the US site. Figure 2 shows that the distribution of these signatures is highly skewed, by plotting the total number of signatures for each petition against the rank order of the petition by total number of signatures. It is clear that a small number of petitions have been signed many times each, while a large number of petitions have only been signed a few times each (indeed, half the petitions received only one signature).

On the UK site, only 5 percent of petitions obtained 500 signatures in total, which is similar to the percentage achieving 500 signatures on the previous, No. 10 petition site [13].
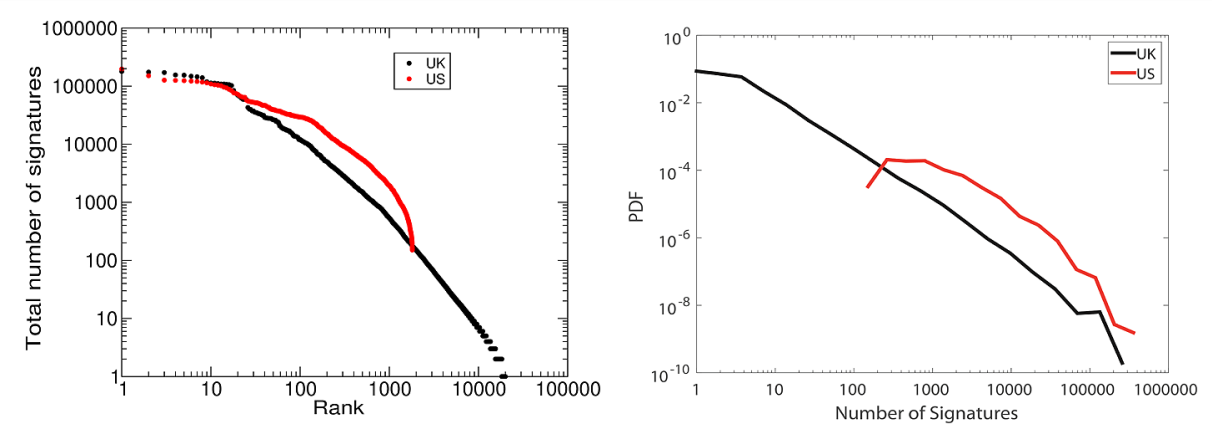

Figure 2 Distribution of the number of signatures to petitions. Left: The total number of signatures per petitions is plotted against the rank order of the petition based on its total number of signatures. Note that the petitions appear on the US website only if they are already signed 100 times. Right: Probability

Distribution Function (PDF) of the number of signatures to the petitions. 
Beyond this, 4 percent of the petitions received 1,000 signatures. Only 0.7 percent attained the 10,000 signatures required for receiving an official response, and 0.1 percent attained the 100,000 signatures required for a parliamentary debate. In the US site, 89 percent of petitions have more than five hundred signatures (note that the petitions in the dataset have at least 100 signatures), suggesting that those that have passed the first bar of 100 signatures have enough momentum to proceed. But only 15 percent reach more than ten thousand and only 0.7 percent reach more than one hundred thousand, the official measure of success.

\subsection{Outreach and growth}

Despite the much larger threshold for success compared to the previous No. 10 platform $(10,000$ vs 500 signatures for an official response and the additional measure of success of 100,000 signatures for a parliamentary debate), a similar pattern in growth emerges suggesting that the first day was crucial to achieving any kind of success. Petition receiving 100,000 signatures after three months, obtained 700 signatures within the first 5 hours on average, 3,000 signatures within the first 10 hours, and 5,000 signatures within the first 24 hours (the averages for all the petitions with less than 100,000 signatures are 3, 7, and 12 signatures respectively). Although there are variations even between successful petitions, the general trend, which will be discussed in the next section, holds for all of the successful petitions. The external measure of 100,000 signatures as success is also clear in Figure 2: petitions rarely grow further once passing the 100,000 signature mark.

Figure 3 and Figure 4 show the number of signatures over time for two example petitions and for all the petitions in the dataset, respectively. In Figure 4 which shows the average growth curves for the cohorts of petitions with similar final number of signatures, it can be easily observed that even those petitions with a large number of signatures, collected the bulk of their signatures very shortly after launching. After a few days, the rate at which petitions grew with new signatures generally slowed significantly for all petitions.

At first glance these findings seem to contradict the normal assumptions of economists and sociologists, who have assumed the production function for collective action to follow an S-shaped curve, with the shape dependent upon the distribution of thresholds in the population [27-30]. Rather than a slow accumulation of supporters building up to critical mass, at which point support 'tips over' into success, petitions that have been successful in receiving large number of signatures demonstrate very rapid early growth, which deceler-
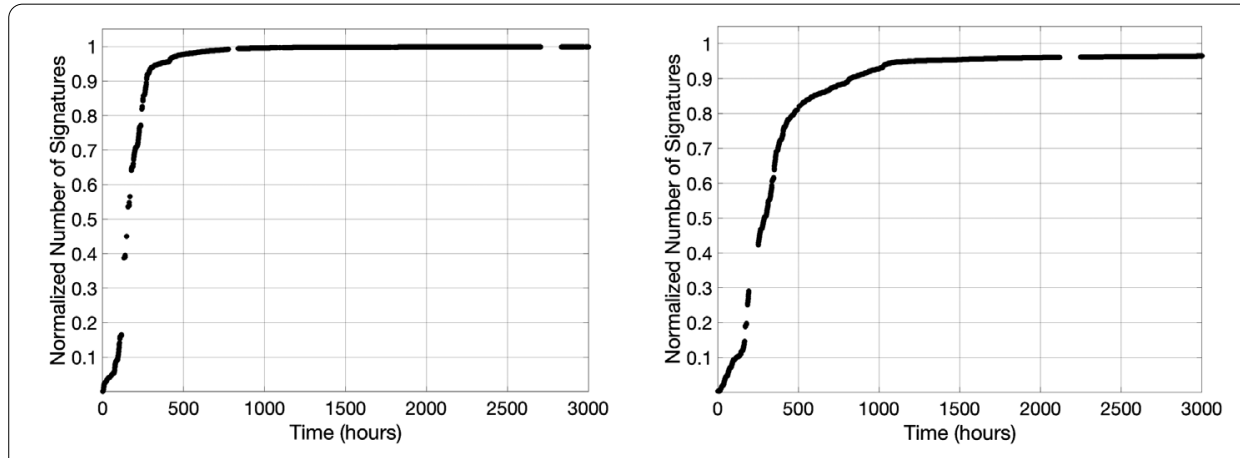

Figure 3 Growth of the number of signatures for 2 example petitions. Left panel: 'Stop the badger cull' and right panel: 'Reconsider West Coast Mainline franchise decision'. 

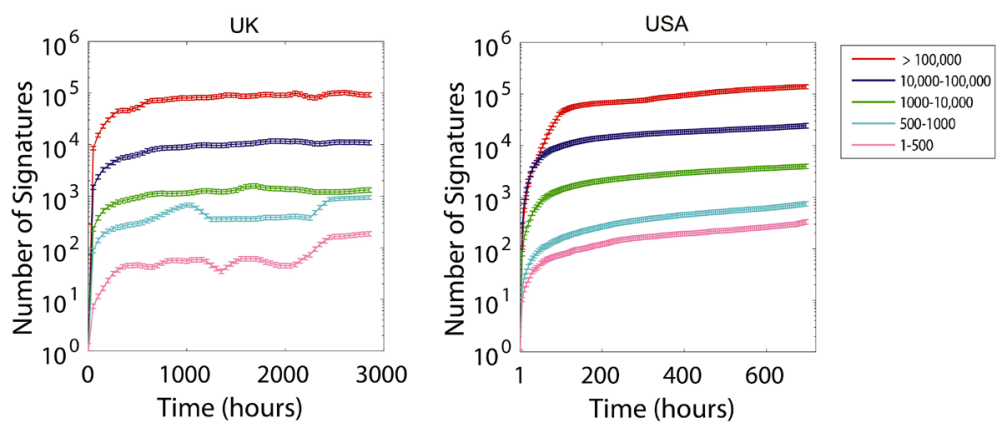

Figure 4 Growth of the number of signatures for all petitions. The UK site in the left panel and the US site in the right panel. Lines are shaded according to the total number of signatures on the petition at the end of the collection period. The curves show the average values within each interval and the error bars show the estimated standard error in calculating the average. The $y$-axis is in logarithmic scale.

ates overtime. We will discuss this point in more details and make numeric comparisons further below.

We attempt to capture the characteristic of early rapid growth and decay that the data reveal, with a model of 'collective attention' decay, drawing on Wu and Huberman [31]. In their model, they calculate a 'novelty' parameter relating to the novelty of news items on Digg (http://digg.com), a news sharing platform, that decays over time. In a more general framework, the decay in attention could occur for different reasons, for example reaching the system size limit, or lack of viral spread. We note that this minimalistic model is only one of many possible models that could be fitted to the data; however, the intrinsic simplicity of the model allows for characterization of the system-level growth behavior of the platform and easy comparison across platforms.

In the model, $N$ agents at the time $t$, bring $N \mu$ new agents in the next step on average, $\mu$ being a multiplication factor. In our case, this would mean that every signature on petition $i$ brings $\mu_{i}$ new signatures in the next hour, leading to exponential growth of rate $\mu_{i}$ in the number of signatures. This model would fit the data we observe empirically quite well for the short period of time directly after a petition's launch (see Figure 3). Very soon, however, the rate decays and new signatures come at a much lower rate.

As in the model of Wu and Huberman [31], we introduce a decay factor to capture this decrease. Specifically, we let the multiplication factor decay by introducing a second factor $r(t)$, which decays in a way that is intrinsic to the medium: each signature at time $t$, on average brings $\mu_{i} r(t)$ new signatures in the next hour. This 'outreach parameter' can change over time and dampen the fast initial growth, correcting for the early saturation observed in the empirical data. The growth equation then reads:

$$
N_{i}(t+1)=N_{i}(t)\left(1+\mu_{i} r(t)\right) .
$$

The number of signatures at time $t$ can be written as:

$$
N_{i}(t)=N_{i}(0)\left(1+\mu_{i} r(0)\right)\left(1+\mu_{i} r(1)\right) \cdots\left(1+\mu_{i} r(t-1)\right) .
$$

In the limit of small time increments, Eq. (2) converts to:

$$
N_{i}(t)=N_{i}(0) \mathrm{e}^{\mu_{i} \sum_{t^{\prime}=0}^{t^{\prime}=t} r\left(t^{\prime}\right)} .
$$


We can assume that the number of signatures at the beginning is one (the initiator of the petition), and therefore averaging of the logarithm of both sides of Eq. (3) leads to:

$$
\mathrm{E}\left[\log \left(N_{i}(t)\right)\right]=\mathrm{E}\left[\mu_{i}\right] \sum_{t^{\prime}=0}^{t^{\prime}=t} r\left(t^{\prime}\right),
$$

where $\mathrm{E}[\cdot]$ indicates the average over the whole sample.

In this framework, each petition has its own fitness and therefore an individual growth rate of $\mu_{i}$, whereas $r$ characterizes the overall outreach power of the platform as a whole. The outreach of the platform is assumed to be independent of the petition fitness and popularity. The disentanglement between these two factors enables us to calculate the outreach factor of the system by considering the whole sample of petitions and averaging over the logarithm of the number of signatures in hourly bins, starting from the time a petition is launched and then calculated in hourly increment at time $t$ and normalized by the logarithm of the number of signatures up to time $t$ as follows:

$$
r(t)=\frac{\mathrm{E}\left[\log \left(N_{i}(t)\right)\right]-\mathrm{E}\left[\log \left(N_{i}(t-1)\right)\right]}{\mathrm{E}\left[\log \left(N_{i}(t)\right)\right]} .
$$

We have calculated the outreach factor as a function of time according to Eq. (5) and illustrated it in Figure 5. The outreach factor decays very fast and, after a time span of 10 hours in the UK data and 30 hours in the US data, reduces to $0.1 \%$.

The model holds, however, only when the growth rates of different petitions come from a localized distribution with finite average and variance. To check this condition, we calculate the ratio between the sample average and variance of $\log (N(t))$ for different $t$ and

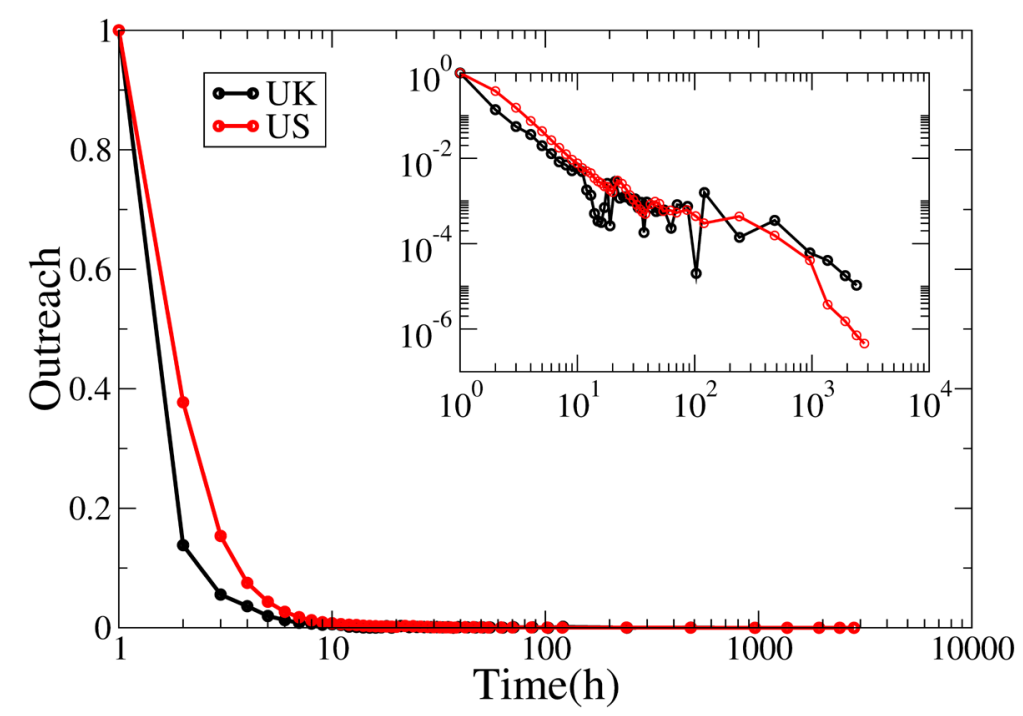

Figure 5 The outreach factor for the petition sites as a whole calculated according to Eq. (5). The inset shows the same quantity on a log-log scale. 
Figure 6 The sample average of $\log (N)$ against the variance of the same quantity to validate the multiplicative model according to Eq. (6). The solid line is a linear fit of the form of $y=a x$ with $a=1.872 \pm 0.03$.

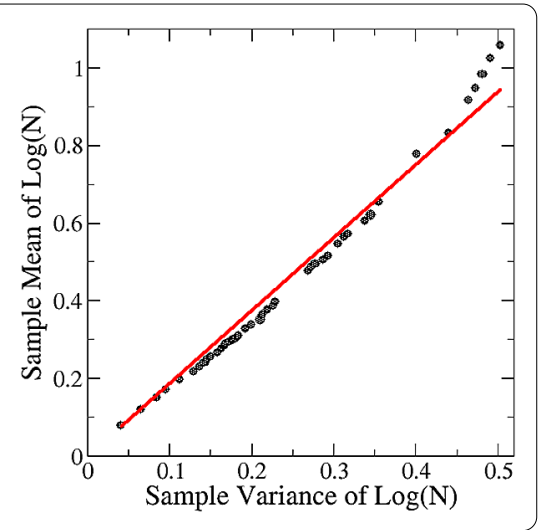

check the following linear relation holds:

$$
\frac{\mathrm{E}[\log (N(t))]}{\operatorname{Var}[\log (N(t))]}=\frac{\mathrm{E}\left[\mu_{i}\right] \sum_{t^{\prime}=0}^{t^{\prime}=t}\left(r\left(t^{\prime}\right)\right)}{\operatorname{Var}\left[\mu_{i}\right] \sum_{t^{\prime}=0}^{t^{\prime}=t}\left(r\left(t^{\prime}\right)\right)}=\frac{\mu}{\sigma^{2}},
$$

where $\mu$ and $\sigma$ are the sample mean and the standard deviation of the individual growth rates. If the multiplicative model and the framework are valid, the ratio between the sample mean and the variance of $\log (N)$ should remain constant over time. Figure 6 plots these two values and demonstrates the ratio does indeed remain constant. The root mean square of residuals from a diagonal line is 0.03 .

Furthermore, Eq. (3) can be simplified by normalizing the number of signatures to the final number of signatures achieved up to time $t_{\max }, N_{i}^{\text {norm }}(t)=N_{i}(t) / N_{i}\left(t_{\max }\right)$, and considering that the number of signatures at the beginning of the process is one for all petitions $N_{i}(0)=1$ :

$$
N_{i}^{\text {norm }}(t)=\mathrm{e}^{\mu_{i}\left(f(t)-f\left(t_{\max }\right)\right)}
$$

and

$$
\mathrm{E}\left[\log \left(N_{i}^{\mathrm{norm}}(t)\right)\right]=\mu\left(f(t)-f\left(t_{\max }\right)\right),
$$

where $f(t)=\sum_{t^{\prime}=0}^{t^{\prime}=t} r\left(t^{\prime}\right)$ is a function only depending on time and the evolution of the novelty factor over time. Equation (8) suggests that if we plot the average of normalized growth curves for all the petitions in logarithmic space, they will collapse into a single curve. This average is plotted in Figure 7 along with the model fit and two logistic curves of the following forms:

$$
N(t)=\frac{N_{\max }}{1+B \mathrm{e}^{-C t}}
$$

and

$$
N(t)=\frac{N_{\max } D^{v}}{\left(D+B \mathrm{e}^{-C t}\right)^{v}} .
$$

Since we have normalized the number of signatures to its maximum, we set $N_{\max }=1$. The curve described in Eq. (9) is the simple logistic function, aka S-curve, that now has two 


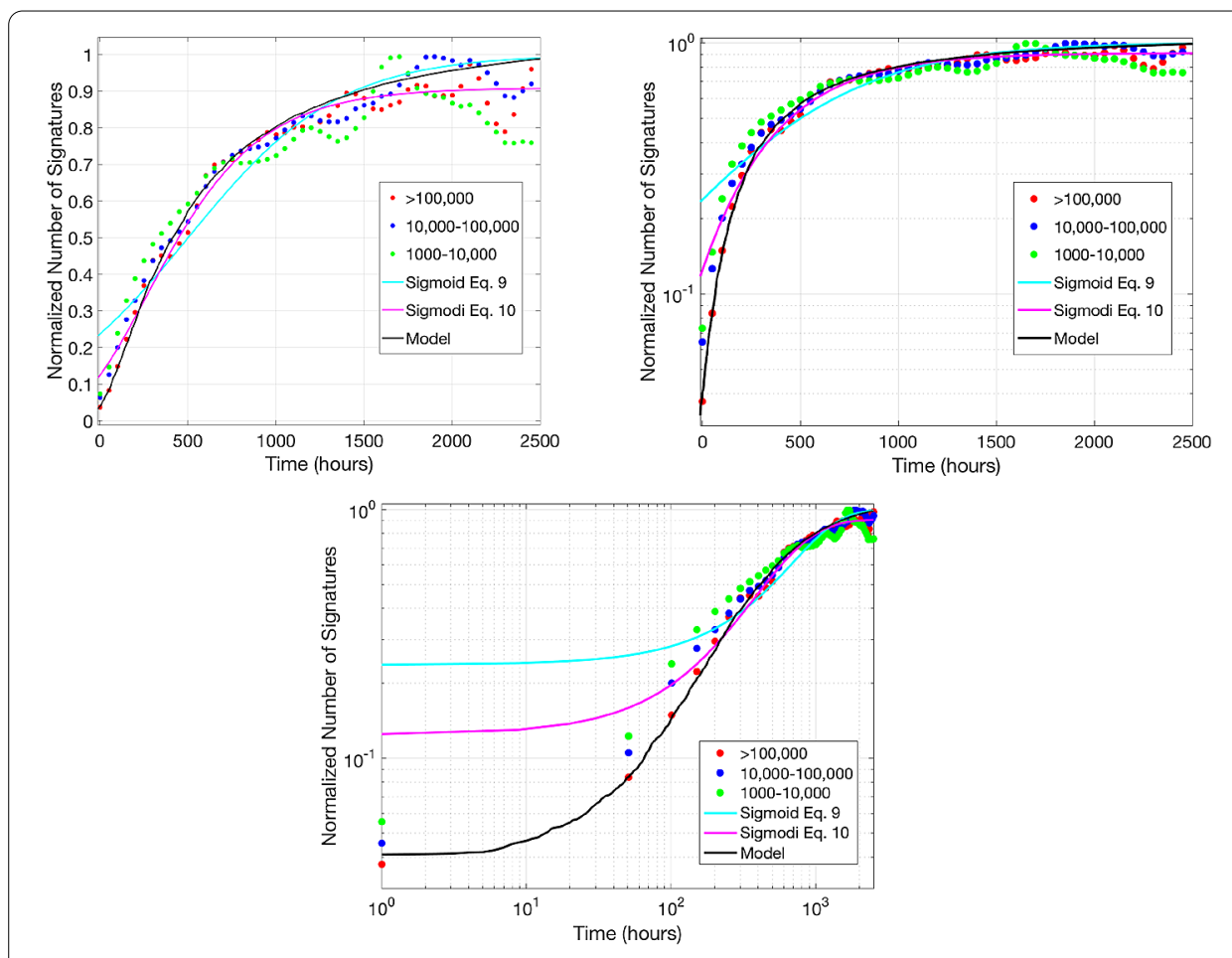

Figure 7 Data collapse of the normalized number of signatures for different cohorts of petitions. The model fits the data much better than a Sigmoid curve.

free parameters $(B$ and $C)$. In addition to that, we also check the fit for the curve described in Eq. (10) which has two more parameters ( $D$ and $v$ ) allowing for an accelerated growth similar to what we observed in the data. We use an iterative least squares optimization method as implement in Matlab to find the best fit of the curves to the data.

To fit the model to the data in Figure 7, we simulate the process described in Eq. (1) with $r(t) \sim r_{0} t^{-2.5}$ (taken from Figure 5) and $\mu_{i}$ taken from a uniform distribution with an average of $\mu$ (tuned for the best fit to the data through an iterative least square method).

It is evident that the explosive early growth is well captured in the model, whereas both $\mathrm{S}$-curves fail to fit the data. The deviation between the data and S-curves is more evident in the semi-log and log-log plots of Figure 7. To further quantify the goodness of the fits, we calculated the normalized average residuals to be $0.013,0.81$, and 6.23 for the multiplicative model, sigmoid Eq. (9), and sigmoid Eq. (10) respectively. These results indicate that the model of Eq. (3) provides a better fit to the data and considering that Eq. (10) has four free parameters (compared to our model with three), one can confidently reject the superiority of a logistic S-shaped model.

\section{Discussion and conclusions}

This paper analyzes growth patterns in petitions created on the UK and US governments petitions platforms. We find that most petitions started on the platform failed to achieve any real traction, while the minority of petitions that did amass a large number of signatures did so quickly. The distribution of the number of signatures per petition is highly skewed: a few petitions captured a large number of signatures, while most petitions received very few signatures. By applying a simple multiplicative growth model, we have 
illustrated that the intrinsic time scales of the platforms are very short and the growth of signatures on petitions exhibits rapid dynamics.

These findings have immediate application to petition platform designers as well as to petitioners themselves. Although the UK site defaults to having petitions active for one year, our analysis indicates that most signatures are added shortly after a petition is launched. Shorter deadlines such as the three/six week deadlines of German petitions [21] or the one month deadline of US petitions on the WeThePeople site, therefore, might produce similar outcomes without the clutter of old petitions on the sites. We are examining this design option through a comparison with the US and German petitions platforms, and advising policy-makers regarding the optimal design. ${ }^{\mathrm{b}}$ The analysis also highlights the importance for petitioners of gaining early traction. Experimental research shows that the willingness of individuals to sign a petition varies with the social information provided on how many other individuals have signed the petition already [32,33]. The early growth of petitions reflects a similar feedback loop as the petitions with the most signatures get further signatures. The outreach factor, however, decays very quickly indicating that the window of opportunity for success is very small.

The outreach factor is fit to all the data on the platforms and reflects the collective decay in attention to the platforms as a whole. In comparison to the work by Wu and Huberman [31] on the Digg news sharing website, where the outreach factor (there called novelty) decayed 'faster than power law', with a half-life of approximately one hour, the petition outreach factor decays very close to a power law.

Thus, attention to petitions lasts somewhat longer than attention to the news links analyzed by Wu and Huberman [31]. It will be useful in future research to compare the outreach of various platforms, political and non-political, to understand the variations in the dynamics of different platforms. The growth patterns revealed by this analysis challenge our current understanding of collective action in online environments.

The explanation for the different patterns observed here may derive depending on how petition signatories come to find out about petitions. Analytics data for the petition platform provided by the Government Digital Services show the importance of social networking sites in disseminating petitions: about $50 \%$ of users arrive at the UK petitions platform via either Facebook or Twitter (see Figure 8). In addition, previous research has shown that these social media have a very high intrinsic pace [34].

Intuitively, we would expect dissemination via social networking sites to encourage early bursts, because if a user does not receive the information about a petition in their Facebook feed or Twitter stream when it is first sent and appears there, they will not do so unless they seek it out, which evidence from previous research suggests most users do not [35, 36].

Other investigations into the role of social networking sites in the growth of mobilizations have identified an S-shaped curve, with critical mass reached only after 'mid' participants have responded to evidence of the contribution of early participants [4]. Such accounts follow conventional frameworks of collective action in assuming that people have heterogeneous thresholds for joining a mobilization and that until participation reaches the threshold of the majority of potential participants, the joining rate will be slow [28, 37]. In contrast, we find no prolonged period of slow early growth in those mobilizations that were successful, but rather a very rapid growth that starts almost immediately after a petitions' launch. 


\section{Referral Traffic}

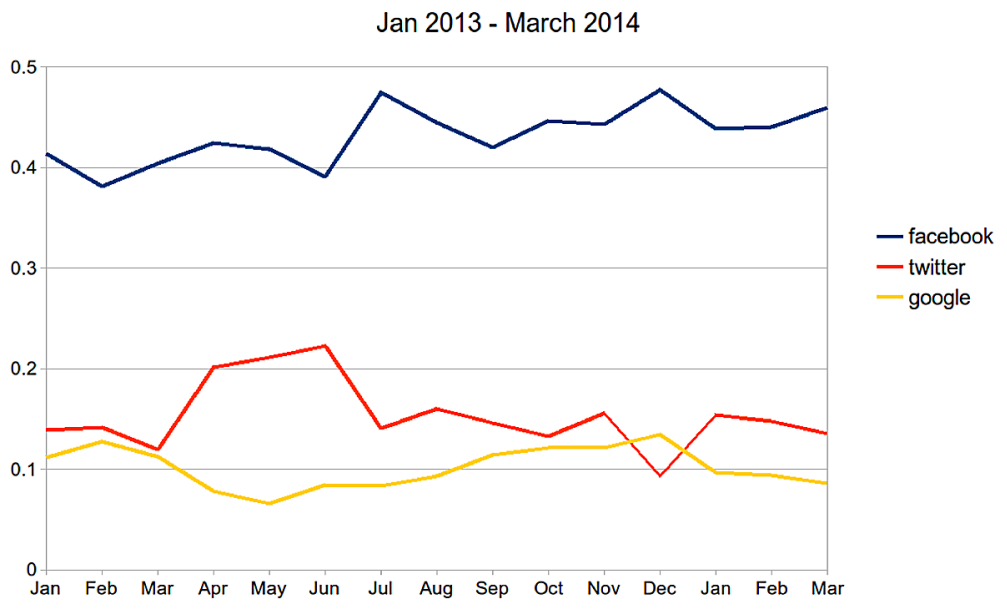

Figure 8 The percentage of all traffic to the UK petitioning website through referral from different

channels. A robust share of the traffic to the site is referred from Facebook and Twitter.

In the context of petitions, it seems that becoming aware of a petition is one of the important elements for eventual success (analogous to sharing news, as in $\mathrm{Wu}$ and $\mathrm{Hu}-$ berman [31]). Signing a petition is a very low cost activity (especially when the name of the signer is not publicly displayed). As such there are many individuals with low enough thresholds to sign, and the main challenge to a petition organizer is reaching these individuals in the crucial time window to be successful.

Although we do not find evidence of the S-shaped curve identified by Gonzalez-Bailon et al. [4], our pattern of early growth could be commensurate with the finding of others that social contagion (where social contagion refers to dissemination) requires exposure to a diversity of sources [38], and that evidence of recruitment bursts would suggest that the effect of multiple and diverse exposures are magnified if they take place in a short time window [4]. These observations suggest that $\mathrm{S}$-shaped growth might not be a proper model to describe Internet-based collective behavior where the costs of participation are very low and the pool of potential participants is very large. Instead, an initial momentum that decays over time seems to be a more relevant model for online mobilization. Further research would be needed to investigate this hypothesis, examining the spread of petitions through social networking sites to understand variations in the dynamics of different platforms.

Acknowledgements

We thank Soodabeh Milanlouei for an insightful discussion on the generalized logistic function. We also thank the anonymous reviewers and the EPJ Data Science Editors for the comments and suggestions.

Funding

This work was supported by the Economic and Social Research Council [grant number RES-051-27-0331].

Availability of data and materials

All the data used in the paper are publicly available $[25,26]$

Ethics approval and consent to participate

Not applicable.

Competing interests

The authors declare that they have no competing interests. 


\section{Consent for publication}

Not applicable.

\section{Authors' contributions}

TY has performed the data analysis and modeling. SH has collected the data. HM designed the research project. All the authors have contributed to writing and reviewed the manuscript.

\section{Endnotes}

a http://www.whitehouse.gov/blog/2012/09/24/happy-birthday-we-people.

b http://www.parliament.uk/business/committees/committees-a-z/commons-select/procedure-committee/ inquiries/parliament-2010/e-petitions.

\section{Publisher's Note}

Springer Nature remains neutral with regard to jurisdictional claims in published maps and institutional affiliations.

\section{Received: 5 February 2016 Accepted: 17 August 2017 Published online: 29 August 2017}

\section{References}

1. Margetts H, John P, Hale S, Yasseri T (2015) Political turbulence: how social media shape collective action. Princeton University Press, Princeton

2. Harlow S, Harp D (2012) Collective action on the web. Inf Commun Soc 15(2):196-216

3. Borge-Holthoefer J, Moreno Y, Yasseri T (2016) Editorial: at the crossroads: lessons and challenges in computational social science. Front Phys 4:37

4. González-Bailón S, Borge-Holthoefer J, Rivero A, Moreno Y (2011) The dynamics of protest recruitment through an online network. Sci Rep 1:197

5. Borge-Holthoefer J, Rivero A, García I, Cauhé E, Ferrer A, Ferrer D, Francos D, Iniguez D, Pérez MP, Ruiz G, Sanz F, Serrano F, Vinas C, Tarancón A, Moreno Y (2011) Structural and dynamical patterns on online social networks: the Spanish May 15th movement as a case study. PLoS ONE 6:e23883

6. Ghonim W (2012) Revolution 2.0: the power of the people is greater than the people in power: a memoir. Houghton Mifflin, New York

7. Yasseri T, Sumi R, Rung A, Kornai A, Kertész J (2012) Dynamics of conflicts in Wikipedia. PLoS ONE 7(6):e38869

8. Iñiguez G, Török J, Yasseri T, Kaski K, Kertész J (2014) Modeling social dynamics in a collaborative environment. EPJ Data Sci 3:1

9. Conover MD, Gonçalves B, Flammini A, Menczer F (2012) Partisan asymmetries in online political activity. EPJ Data Sci $1: 6$

10. Chmiel A, Sienkiewicz J, Paltoglou G, Buckley K, Skowron M, Thelwall M, Kappas A, Hołyst J (2014) Collective emotions online. In: Agarwal N, Lim M, Wigand RT (eds) Online collective action. Lecture notes in social networks. Springer, Berlin, pp 59-74

11. Hale SA, John P, Margetts H, Yasseri T (2014) Investigating political participation and social information using big data and a natural experiment. In: 2014 annual meeting and exhibition of the American Political Science Association, Washington, DC. https://arxiv.org/abs/1408.3562

12. Wright S (2012) Assessing (e-)democratic innovations: "democratic goods" and Downing Street e-petitions. J Inf Technol Polit 9(4):453-470. doi:10.1080/19331681.2012.712820. http://www.tandfonline.com/doi/abs/10.1080/19331681.2012.712820

13. Hale SA, Margetts H, Yasseri T (2013) Petition growth and success rates on the UK No. 10 Downing Street website. In: Proceedings of the 5th annual ACM web science conference. WebSci '13. ACM, New York, pp 132-138. doi:10.1145/2464464.2464518.

14. Parry G, Moyser G, Day N (1992) Political participation and democracy in Britain. Cambridge University Press, Cambridge

15. Whyte A, Renton A, Macintosh A (2005) e-petitioning in Kingston and Bristol: evaluation of e-petitioning in the loca e-democracy national project. International Teledemocracy Centre, Napier University, Edinburgh

16. Smith G (2009) Democratic innovations: designing institutions for citizen participation. Cambridge University Press, Cambridge

17. Escher T (2011) Writetothem.com: analysis of users and usage for UK citizens online democracy. UK Citizens Online Democracy

18. Chadwick A (2008) Web 2.0: new challenges for the study of e-democracy in an era of informational exuberance. J Law Policy Inf Soc 5(1):9-41

19. Fox R, Gibbons V, Korris M (2012) What next for e-petitions. Technical report, Hansard Society

20. Lindner R, Riehm U (2011) Broadening participation through e-petitions? An empirical study of petitions to the German Parliament. Policy Internet 3(1):63-85

21. Jungherr $A$, Jürgens $P(2010)$ The political click: political participation through e-petitions in Germany. Policy Internet 2(4):131-165. doi:10.2202/1944-2866.1084

22. Schmidt J-H, Johnsen K (2014) On the use of the e-petition platform of the German Bundestag. Preprint. doi:10.2139/ssrn.2444672

23. Bennett WL, lyengar S (2008) A new era of minimal effects? The changing foundations of political communication. J Commun 58(4):707-731

24. Farrell H (2012) The consequences of the Internet for politics. Annu Rev Pol Sci 15(1):35-52

25. Margetts HZ, Hale SA, Yasseri T (2016) Petitions: gov.uk petitioning website. UK Data Archive, Colchester, Essex. doi:10.5255/UKDA-SN-851614

26. Margetts HZ, Hale SA, Yasseri T (2015) We the people: the US petitioning website. UK Data Archive, Colchester, Essex. doi:10.5255/UKDA-SN-851616 
27. Granovetter M (1978) Threshold models of collective behavior. Am J Sociol 83(6):1420-1443

28. Schelling T (1978) Micromotives and macrobehavior. Norton, New York

29. Centola DM (2013) Homophily, networks, and critical mass: solving the start-up problem in large group collective action. Ration Soc 25(1):3-40. doi:10.1177/1043463112473734. http://rss.sagepub.com/content/25/1/3.abstract

30. Marwell G, Oliver P (1993) The critical mass in collective action: a micro-social theory. Cambridge University Press, Cambridge

31. Wu F, Huberman BA (2007) Novelty and collective attention. Proc Natl Acad Sci USA 104(45):17599-17601. doi:10.1073/pnas.0704916104. http://www.pnas.org/content/104/45/17599.abstract

32. Margetts $H$, John P, Escher T, Reissfelder S (2011) Social information and political participation on the Internet: an experiment. Eur Polit Sci Rev 3(3):321-344. doi:10.1017/S1755773911000129

33. Margetts HZ, John P, Hale SA, Reissfelder S (2013) Leadership without leaders? Starters and followers in online collective action. Polit Stud 63(2):278-299

34. Bright J (2014) Does the news media set the social agenda? Working paper

35. Lin Y-R, Margolin D, Keegan B, Baronchelli A, Lazer D (2013) \#bigbirds never die: understanding social dynamics of emergent hashtags

36. Gleeson JP, Cellai D, Onnela J-P, Porter MA, Reed-Tsochas F (2013) A simple generative model of collective online behaviour. Preprint. arXiv:1305.7440

37. Granovetter M (1978) Threshold models of collective behavior. Am J Sociol 83(6):1420-1443

38. Centola D, Macy M (2007) Complex Contagions and the Weakness of Long Ties. Am J Sociol 113(3):702-734

\section{Submit your manuscript to a SpringerOpen ${ }^{\circ}$} journal and benefit from:

- Convenient online submission

- Rigorous peer review

Open access: articles freely available online

High visibility within the field

- Retaining the copyright to your article

Submit your next manuscript at $>$ springeropen.com 